\title{
Kinerja Sistem Fertigasi Autopot pada Budidaya Tomat Cherry
}

\section{The Performance of Autopot Fertigation System on Cherry Tomato Cultivation}

\author{
Sophia Dwiratna ${ }^{1}$, Nurpilihan Bafdal ${ }^{1}$, Dwi Rustam Kendarto ${ }^{1}$ \\ ${ }^{1}$ Departemen Teknik Pertanian dan Biosistem, Fakultas Teknologi Industri Pertanian, Universitas Padjadjaran \\ Jl. Raya Bandung-Sumedang Km. 21 Jatinangor 43563 \\ Email korespondensi : dwiratnasophia@gmail.com
}

\begin{abstract}
ABSTRAK
Air merupakan faktor penting dalam sektor pertanian dan juga menjadi salah satu faktor pembatas pertama produksi pertanian. Tindakan konservasi dan peningkatan efisiensi penggunaan air dapat menjadi salah satu alternatif untuk mengatasi kekurangan air. Salah satu teknologi yang dapat mengoptimalkan penggunaan air adalah dengan menggunakan sistem fertigasi autopot. Sistem fertigasi autopot adalah teknologi pemberian larutan nutrisi sesuai kebutuhan air tanaman tanpa menggunakan listrik untuk mensirkulasikan larutan nutrisi. Penelitian ini bertujuan untuk menguji kehandalan kinerja sistem fertigasi autopot pada budidaya tomat cherry berdasarkan parameter keseragaman irigasi, penggunaan air konsumtif dan efisiensi penggunaan air. Penelitian ini dilaksanakan di greenhouse ALG, Universitas Padjadajaran menggunakan metode analisis deskriptif. Budidaya tomat cherry menggunakan media tanam campuran arang sekam dan zeolit dengan perbandingan 9:1 dengan ketinggian media $15 \mathrm{~cm}$. Hasil penelitian menunjukkan bahwa sistem fertigasi autopot memiliki kinerja yang sangat baik, berdasarkan nilai keseragaman irigasi rata-rata sebesar $89,4 \%$ dan efisiensi penggunaan air per autopot sebesar $22,93 \mathrm{~kg} / \mathrm{m}^{3}$. Seluruh air irigasi yang diberikan hanya digunakan untuk memenuhi kebutuhan air tanaman saja, tanpa ada yang hilang karena drainase maupun rembesan.
\end{abstract}

Kata kunci: fertigasi, autopot, efisiensi irigasi, kinerja irigasi, soilless culture

\begin{abstract}
Water is one crucial factor in agriculture sector and becomes a first barrier factor in agriculture production. Conservation and the increasing water use efficiency can become an alternative to prevent water deficiency. One of the technologies to optimize water use is autopot fertigation system. Autopot fertigation system is a technology of providing nutrient solution according to the needs of plant water without using electricity to circulate the nutrient solution. This study aims to test the reliability of the performance of autopot fertigation system on cherry tomato cultivation based on irrigation uniformity parameters, water consumptive use and water use efficiency. This research is done at the Greenhouse ALG of Universitas Padjadjaran by employing descriptive analysis. Cultivation of cherry tomato plant uses a mixture of charcoal husk and zeolite with ratio 9:1 and $15 \mathrm{~cm}$ high. The results showed that the autopot fertigation system performed very well, based on the average irrigation uniformity value of $89.4 \%$ and the water use efficiency of $22.93 \mathrm{~kg} / \mathrm{m}^{3}$. All irrigation water provided is only used to meet the needs of plant water alone, without any loss due to drainage or leakage.
\end{abstract}

Keywords: fertigation, autopot, irrigation efficiency, irrigation performance, soilless culture

\section{PENDAHULUAN}

Air merupakan faktor penting dalam keberhasilan sektor pertanian. Semakin langkanya ketersediaan air untuk pertanian memicu perkembangan teknologi irigasi dengan tingkat efisiensi yang tinggi. Sistem pemberian air yang umum digunakan pada budidaya tomat cherry selama ini adalah sistem irigasi tetes yang memiliki nilai efisiensi irigasi yang cukup tinggi. Pengembangan sistem irigasi saat ini selain harus memiliki nilai efisiensi tinggi juga harus hemat energi. Salah satunya adalah dengan menggunakan sistem autopot. Penggunaan autopot memungkinkan untuk melakukan irigasi bersamaan dengan pemberian pupuk pada tanaman, dikenal sebagai fertigasi dimana air dan nutrisi dilarutkan dalam sebuah drum, dimana nantinya akan dialirkan ke autopot. Menurut Fah (1996) sistem yang digunakan pada autopot memungkinkan tanaman untuk mendapatkan air dan nutrisi secara otomatis karena autopot dilengkapi dengan katup otomatis (smart valve) sebagimana dapat dilihat pada Gambar 1.

1 Alamat Korespondensi: Sophia Dwiratna (dwiratnasophia@gmail.com) Alamat : Program Studi Teknik Pertanian, Universitas Padjadjaran. Jl. Raya Jatinangor Km.21 Jatinangor 43563. Penelitian ini didanai oleh Universitas Padjadjaran melalui dana hibah Academic Leadership Grant 1.1.6

Singkatan : ALG : Academic Leadership Grant; NFT : Nutrient Film Technique; CU: Christiansen Uniformity; WUE: Water Use Efficiency 


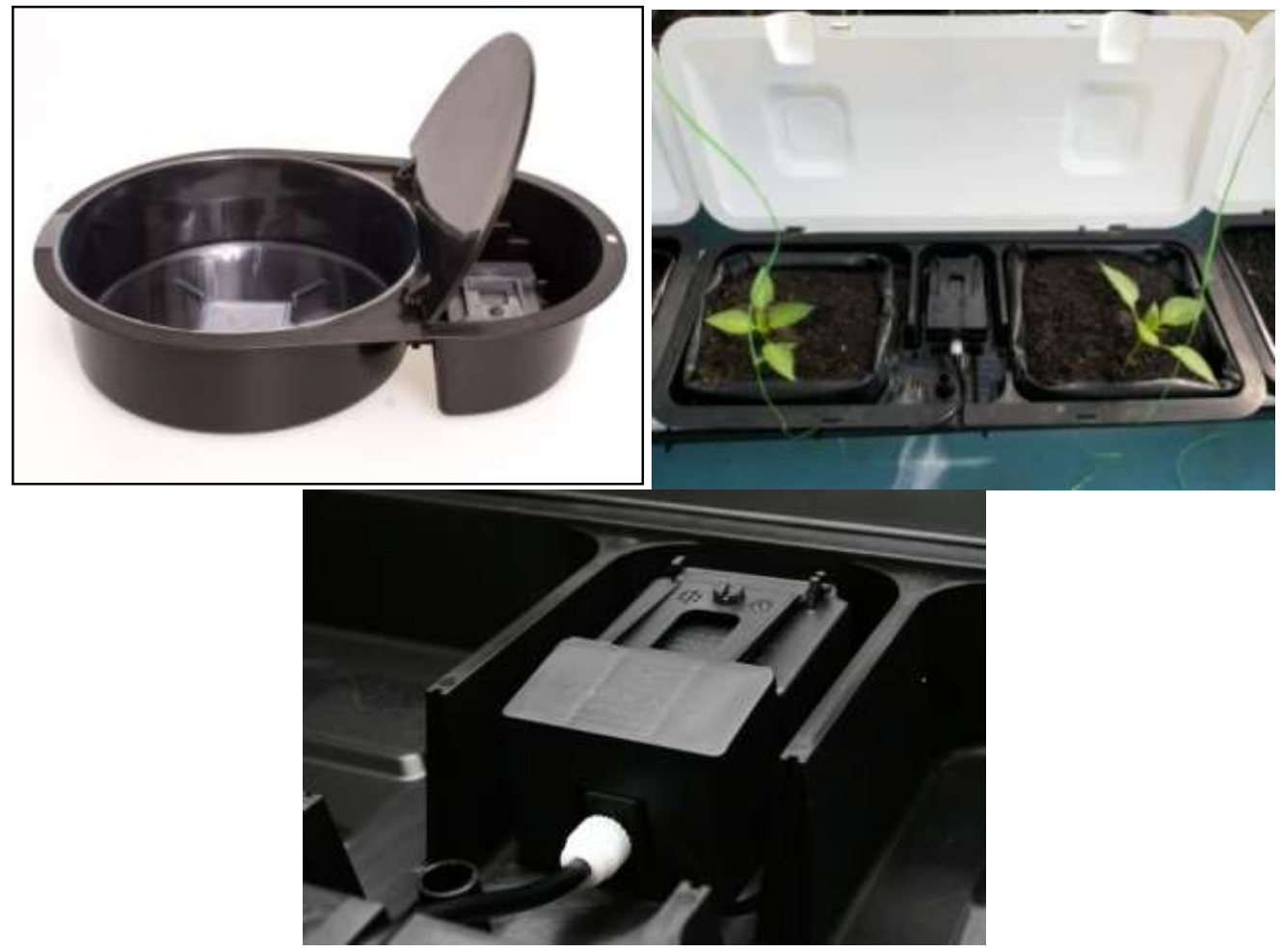

Sumber : Nurpilihan, et., al (2017)(Nurpilihan, Dwiratna and Kendarto, 2017)

Gambar 1. Single dan Double Tray Autopot dengan Smart-valve

Nutrisi yang diberikan kepada tanaman dengan menggunakan autopot lebih efisien dibandingkan dengan cara konvensional yaitu dengan cara disiram maupun tetes. Nurpilihan (2016) menyatakan bahwa katup (smartvalve) yang ada pada autopot berfungsi untuk mengatur tinggi air yang masuk ke dalam autopot dimana air akan keluar apabila ketinggian air pada autopot telah berada pada level minimum dan valve akan menutup apabila air telah berapa pada ketinggian maksimum sehingga air yang diberikan langsung diserap oleh akar tanaman untuk pertumbuhan. Autopot juga dilengkapi dengan penutup, sehingga dapat meminimalisir kehilangan air akibat penguapan dan juga penggunaan autopot dapat mengehemat tenaga kerja karena bekerja dengan prinsip self watering system. Keunggulan lain dari sistm ini adalah tidak menggunakan listrik untuk mensirkulasikan larutan nutrisi sebagaimana pada sistem irigasi tetes, curah maupun NFT yang banyak digunakan pada budidaya hortikultura tanpa tanah (soilless culture). Penggunaan teknologi fertigasi menggunakan autopot dalam budidaya tanaman secara hidroponik merupakan hal baru, saat ini belum diterapkan di Indonesia. Penelitian ini bertujuan untuk menguji kehandalan kinerja sistem fertigasi autopot pada budidaya tomat cherry.

\section{METODE}

Penelitian ini dilaksanakan pada bulan Maret 2017 sampai dengan Juli 2017. Lokasi penelitian bertempat di Greenhouse ALG di kawasan Pedca Utara, Fakultas Teknologi Industri Pertanian, Universitas
Padjadjaran, Kampus Jatinangor, Jawa Barat. Metode penelitian yang digunakan adalah metode analisis deskriptif, yaitu melakukan pengukuran, pengamatan, perhitungan dan analisis data secara kuantitatif terhadap keterkaitan antar variabel dalam pengukuran kinerja sistem fertigasi autopot pada budidaya tomat cherry. Jumlah autopot yang digunakan sebanyak 26, satu autopot digunakan untuk 2 tanaman sehingga jumlah tanaman yang dibudidayakan sebanyak 52 tanaman. Media tanam yang digunakan berupa campuran arang sekam+zeolit dengan komposisi 90\%:10\% dengan ketinggian $15 \mathrm{~cm}$. Parameter yang diamati antara lain adalah penggunaan air konsumtif dan hasil panen tomat cherry. Hasil pengamatan dilapangan dianalisis untuk mengetahui nilai kehandalan sistem fertigasi autopot berdasarkan nilai keseragaman irigasi, keseragaman produksi dan efisiensi penggunaan air. Analisis keseragaman dilakukan dengan menggunakan persamaan Cristiansen Uniformity berikut ini :

$\mathrm{CU}=100\left[1-\frac{\sum\left|\overline{\mathrm{X}}-\mathrm{X}_{\mathrm{i}}\right|}{\mathrm{n} \overline{\mathrm{X}}}\right]$

Dimana :

$\mathrm{CU} \quad=$ Tingkat Keseragaman (\%)

$\mathrm{Xi} \quad=$ Parameter keseragaman (kedalaman air irigasi dan produksi)

$\bar{X} \quad=$ Rata - rata parameter keseragaman

$\mathrm{N} \quad=$ Jumlah pengamatan

Pengukuran kedalaman air dilakukan setiap minggu dengan cara mengukur kedalaman air pada autopot dengan menggunakan mistar. 
Efisiensi penggunaan air (WUE) dapat dihitung dengan menggunakan persamaan dibawah ini (Nurpilihan, Dwiratna and Kendarto, 2017):

WUE $\left(\mathrm{kg} \cdot \mathrm{m}^{-3}\right)=\frac{\text { hasil produksi }}{\text { total penggunaan air }}$

Hasil produksi dinyatakan dalam satuan $\mathrm{kg}$, total air yang digunakan untuk menghasilkan produk dinyatakan dalam $\mathrm{m}^{3}$ serta efisiensi penggunaan air (WUE) dinyatakan dalam satuan $\mathrm{kg} / \mathrm{m}^{3}$.

\section{HASIL DAN PEMBAHASAN}

\section{A. Kedalaman Air Irigasi dan Keseragaman Irigasi}

Keseragaman irigasi dihitung dari tinggi air yang dikeluarkan oleh smart valve pada autopot. Smart valve bekerja mengatur ketinggian air pada autopot. Air akan otomatis keluar jika ketinggian air pada autopot berada pada level minimum dan air akan otomatis terhenti jika ketinggian air berada pada level maksimum. Fah (1996) menyatakan bahwa ketika tersambung dengan sumber air, katup pada autopot akan membuka dan membiarkan larutan nutrisi masuk mengisi penampunan hingga level ketinggian (biasanyanya) $35 \mathrm{~mm}$. Hasil pengukuran kedalaman air pada autopot dapat dilihat pada Gambar 2 berikut.

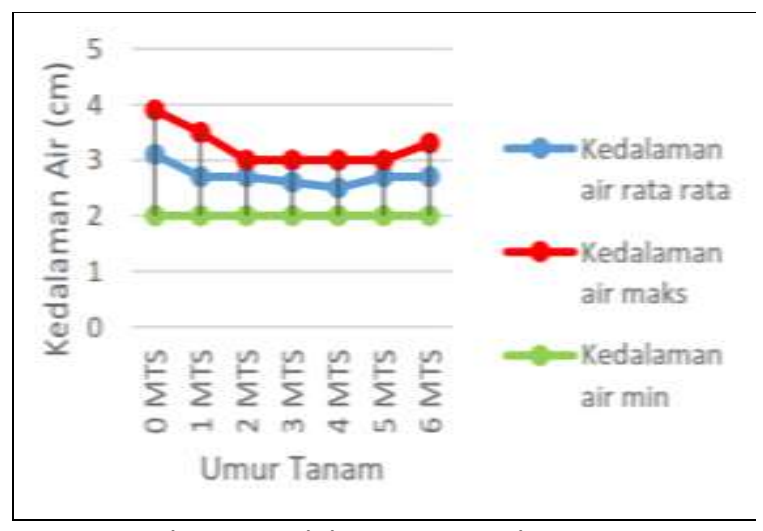

Gambar 2. Kedalaman Air pada Autopot

Hasil pengukuran kedalaman air pada autopot sebagaimana digambarkan pada Gambar 2 menunjukkan bahwa kedalaman air rata-rata dari awal tanam hingga 6 MTS berada dibawah batas maksimal ketinggian air yaitu $35 \mathrm{~mm}$. Kedalaman air rata-rata tertinggi seber $31 \mathrm{~mm}$ pada 0 MTS dan kedalaman air rata-rata terendah pada 4 MTS sebesar $25 \mathrm{~mm}$. Dari grafik dapat dilihat bahwa terjadi penurunan kedalaman air rata-rata dari 0 MTS hingga 4 MTS. Hal tersebut disebabkan adanya penyumbatan pada saluran menuju autopot hingga menghambat debit keluaran air.

Penyumbatan dapat disebabkan adanya zat padat terlarut seperti endapan nutrisi, debu dan benda asing lainnya pada saluran pipa lateral berdiameter $5 \mathrm{~mm}$ menuju autopot. Untuk mendapatkan kedalaman air yang seragam perlu dilakukan pembersihan komponen komponen sebelum dimulai penanaman dan juga dibutuhkan pemeliharaan dan pembersihan secara berkala agar dapat mencegah terjadinya penyumbatan pada katup dan jaringan pipa.

Perhitungan keseragaman kedalaman air atau koefisien keseragaman air irigasi pada sistem autopot dilakukan dengan menggunakan Persamaan 1. Hasil analisis keseragaman irigasi dapat dilihat pada Gambar 3 berikut.

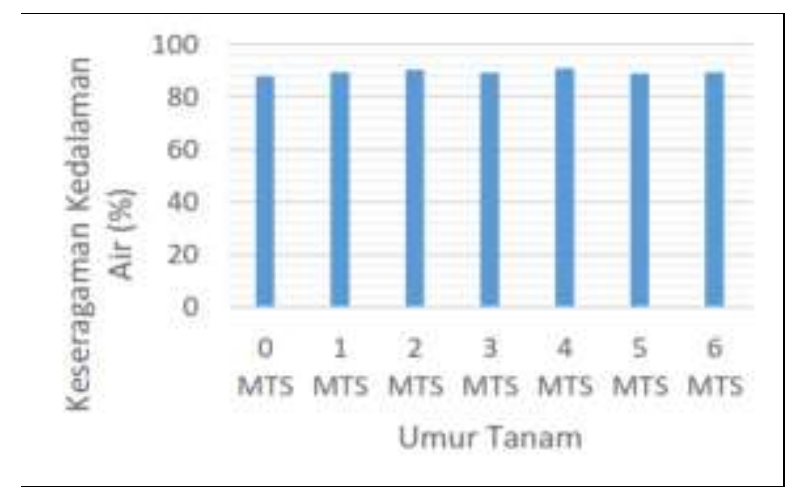

Gambar 3. Keseragaman Irigasi Autopot System

Untuk mendapatkan pertumbuhan yang merata diperlukan keseragaman pemberian air untuk setiap tanaman. Nilai rata-rata keseragaman irigasi pada autopot berkisar antara 87,95-90,77 \% sebagaimana terlihat pada Gambar 3, sehingga dapat dikategorikan "Baik".

\section{B. Penggunaan Air Konsumtif}

Kebutuhan air tanaman adalah jumlah air yang diperlukan untuk mengganti kehilangan air akibat proses penguapan (evaporasi), transpirasi dan aktivitas metabolisme tanaman (Allen et al., 1998; Savva and Frenken, 2002; Surendran et al., 2015). Besar kebutuhan air untuk pertumbuhan tanaman ditentukan oleh jenis tanaman, fase pertumbuhan tanaman dan faktor iklim (Oweis, Farahani and Hachum, 2011; Bouraima, Weihua and Chaofu, 2015). Nilai evapotrasnpirasi tanaman (ETc) didapat dari penggunaan air konsumtif tanaman yang dihitung dari penurunan air pada drum nutrisi setiap harinya sebagaimana ditunjukkan pada Gambar 4.

Dapat dillihat pada Gambar 4 bahwa nilai evapotranspirasi tanaman (ETc) meningkat seiring dengan pertumbuhan dan perkembangan tanaman dan menurun pada masa akhir tanam. Nilai ETc pada fase awal yaitu pada umur tanaman 1-20 hari sebesar 3,27 $\mathrm{mm}$, nilai ETc pada fase perkembangan pada umur tanaman 21-40 hari yaitu sebesar $37,96 \mathrm{~mm}$, nilai ETc pada fase pertengahan pada umur tanaman 41-135 hari yaitu sebesar $324,94 \mathrm{~mm}$ dan pada fase akhir nilai ETc sebesar 15,58 mm pada umur tanaman 136-145 hari. Sementara itu, jumlah air yang yang digunakan tanaman tomat cherry pada setiap fase tumbuh dapat dilihat pada Tabel 1. 


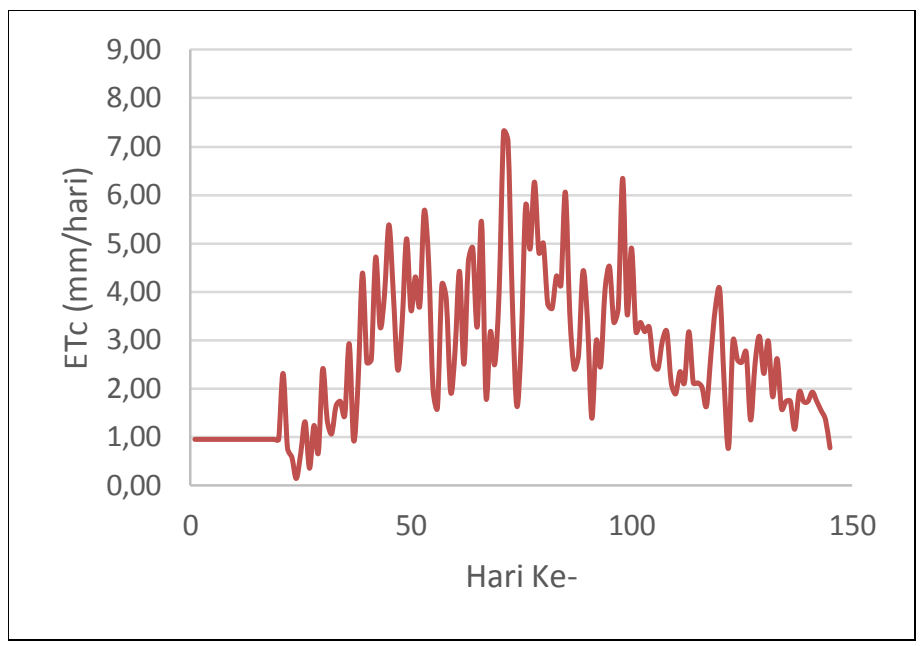

Gambar 4. Penggunaan air konsumtif tomat cherry menggunakan sistem fertigasi autopot

Tabel 1. Total Penggunaan Air Konsumtif Per Periode Tumbuh

\begin{tabular}{|c|c|c|}
\hline \multirow[t]{2}{*}{ Fase Pertumbuhan } & \multicolumn{2}{|c|}{$\begin{array}{l}\text { Penggunaan air konsumtif per } \\
\text { tanaman }\end{array}$} \\
\hline & Liter & $\mathrm{mm}$ \\
\hline Fase awal (20 hari) & 0,33 & 3,27 \\
\hline Fase perkembangan (20 hari) & 6,97 & 37,96 \\
\hline Fase Pertengahan (95 hari) & 59,62 & 324,94 \\
\hline Fase akhir (10) & 2,86 & 15,58 \\
\hline Total & 69,78 & 381,75 \\
\hline
\end{tabular}

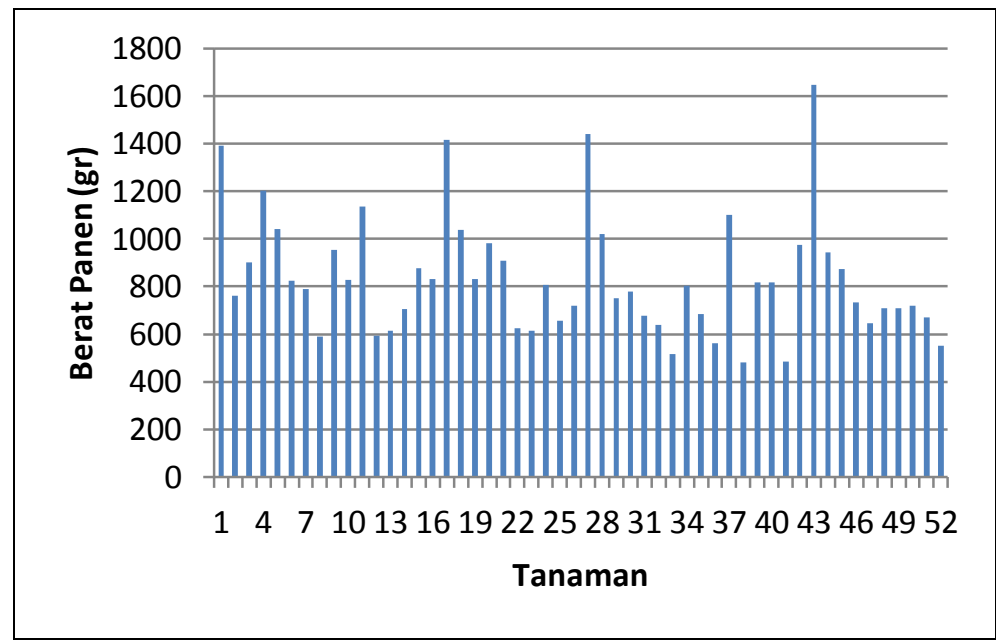

Gambar 5. Berat Panen Tomat Cherry Per Tanaman

Pada Tabel 1 dapat dilihat bahwa total air yang digunakan tanaman tomat cherry dalam satu periode tumbuh yaitu sebesar 69,78 liter/tanaman. Penggunaan air terus meningkat pada setiap fasenya dan terjadi penurunan pada fase akhir. Penggunaan air terbanyak terdapat pada fase pertengahan sebesar 59,62 liter/tanaman dan penggunaan air paling sedikit terjadi pada fase akhir yaitu sebesar 0,33 liter/tanaman. Total kebutuhan air tanaman tomat cherry selama satu periode tanam menggunakan autopot adalah sebesar $382 \mathrm{~mm}$. Allen et al., (1998 dan Suzuki et al., (2015) menyatakan bahwa total kebutuhan air tanaman tomat adalah sebesar $600 \mathrm{~mm}$. Jika dibandingkan maka penggunaan air untuk memenuhi kebutuhan air tanaman tomat cherry menggunakan autopot lebih sedikit dan lebih efisien.

\section{Efisiensi Penggunaan Air}

Menurut Suzuki et al., (2015) cara menentukan indeks panen adalah dengan membedakan perubahan fisik-kimia yang terjadi selama proses kemasakan buah dari tingkat kemasakan muda sampai tua, berturut-turut adalah green mature, breaker, turning, pink, light red, dan red. Pemanenan dilakukan secara periodik yaitu 
selang 2-3 hari sekali. Pengukuran bobot hasil panen tanaman tomat cherry ini dilakukan dengan menimbang buah per autopot. Hasil panen tomat cherry yang dibudidayakan dengan menggunakan sistem fertigasi autopot dapat dilihat pada Gambar 5.

Gambar 5 diatas menunjukkan berat panen tomat cherry per tanaman. Nilai maksimum berat panen per tanaman adalah sebesar 1,6 kg dengan rata rata berat panen sebesar per tanaman sebesar $0.834 \mathrm{~kg}$. Hasil pengamatan sebelumnya diketahui bahwa nilai total penggunaan air per tanaman adalah sebesar 69,78 liter. Dalam satu autopot terdapat 2 tanaman, sehingga dengan menggunakan Persamaan 2, diperoleh nilai efisiensi penggunaan air untuk tomat cherry yang dibudidayakan menggunakan sistem fertigasi autopot sebesar $22,93 \mathrm{~kg} / \mathrm{m}^{3}$. Nilai ini sangat efisien, mengingat air irigasi yang diberikan hanya digunakan untuk memenuhi kebutuhan air tanaman saja.

\section{KESIMPULAN}

Sistem fertigasi autopot memiliki kinerja yang sangat baik, berdasarkan nilai keseragaman irigasi ratarata sebesar $89,4 \%$ dan efisiensi penggunaan air sebesar $22,93 \mathrm{~kg} / \mathrm{m}^{3}$. Seluruh air irigasi yang diberikan hanya digunakan untuk memenuhi kebutuhan air tanaman saja, tanpa ada yg hilang karena drainase maupun rembesan.

\section{UCAPAN TERIMAKASIH}

Atas terselenggaranya penelitian ini penulis mengucapkan terimakasih kepada Rektor Universitas Padjadjaran yang telah mendanai penelitian melalui skim hibah penelitian Academic Leadership Grant 1.1.6, juga kepada Direktorat Riset, Pengabdian Masyarakat dan Inovasi Universitas Padjadjaran yang telah memberikan fasilitas penelitian.

\section{DAFTAR PUSTAKA}

Allen, R. G., Pereira, L. S., Raes, D. and Smith, M. (1998) 'Crop evapotranspiration: Guidelines for computing crop requirements', Irrigation and Drainage Paper No. 56, FAO, (56), p. 300. doi: 10.1016/j.eja.2010.12.001.

Bouraima, A. K., Weihua, Z. and Chaofu, W. (2015) 'Irrigation water requirements of rice using
Cropwat model in Northern Benin', International Journal of Agricultural and Biological Engineering, 8(2), pp. 58-64. doi: 10.3965/j.ijabe.20150802.1290.

Fah, J. (1996) Hydroponics Made Easy : A Useful Guide for Novice and Intermediate Users of Hydroponics. Bayswater, Vic : Agromatic Corporation Pty Ltd.

Nurpilihan (2016) 'Rainfall Harvesting as Resources of Self Watering Fertigation System with Various Growing Medias', International Journal on Advanced Science, Engineering and Information Technology (IJASEIT), 6(5), pp. 787-792. doi: DOI:10.18517/ijaseit.6.5.1158.

Nurpilihan, B., Dwiratna, S. and Kendarto, D. R. (2017) 'Impact of Water Use on Paprika ( Capsicum annum ) by Using Fertigation and Autopot System Combined with Numerous Growing Media', Asian Journal of Plant Sciences, 16(3), pp. 149-159. doi: 10.3923/ajps.2017.149.159.

Oweis, T. Y., Farahani, H. J. and Hachum, A. Y. (2011) 'Evapotranspiration and water use of full and deficit irrigated cotton in the Mediterranean environment in northern Syria', Agricultural Water Management. Elsevier B.V., 98(8), pp. 1239-1248. doi: 10.1016/j.agwat.2011.02.009.

Savva, A. P. and Frenken, K. (2002) Irrigatin Manual Module 4. Crop Water Requirements and Irrigation Scheduling. Harare, Zimbabwe: Food and Agriculture Organization (FAO).

Surendran, U., Sushanth, C. M., Mammen, G. and Joseph, E. J. (2015) 'Modelling the Crop Water Requirement Using FAO-CROPWAT and Assessment of Water Resources for Sustainable Water Resource Management: A Case Study in Palakkad District of Humid Tropical Kerala, India', Aquatic Procedia. Elsevier B.V., 4(Icwrcoe), pp. 1211-1219. doi: 10.1016/j.aqpro.2015.02.154.

Suzuki, M., Umeda, H., Matsuo, S., Kawasaki, Y., Ahn, D., Hamamoto, H. and Iwasaki, Y. (2015) 'Effects of relative humidity and nutrient supply on growth and nutrient uptake in greenhouse tomato production', Scientia Horticulturae, 187, pp. 4449. doi: 10.1016/j.scienta.2015.02.035. 